\title{
Influenza pandémica a un año de la primera ola. ¿Qué podemos decir ahora?
}

\author{
Cecilia Perret $P$.
}

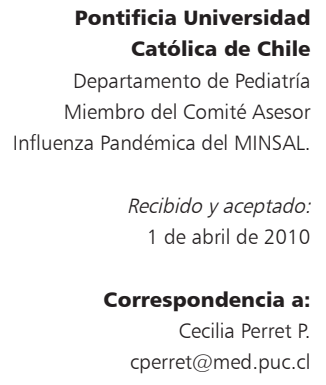

Católica de Chile

Departamento de Pediatría Miembro del Comité Aseso Recibido y aceptado: rrespondencia a:

\begin{abstract}
Pandemic influenza one year after the first wave. What did we learn?
During year 2009 our nation experimented the first influenza pandemic wave due to the novel influenza A(H1N1) 2009 virus that emerged in the Northern hemisphere at the end of April, 2009. Estimated attack rate was about 6 to $12 \%$ affecting mainly to school children who presented with a mild disease. Age groups with highest risk of hospitalization were elderly people and children under 5 years old. Elderly patients and patients with co-morbidities had the highest risk to die. We have learnt that clinical diagnosis of influenza has a laboratory confirmation in about $80 \%$ of cases but its correlation is lower in kids under 5 years old, especially in infants when RSV co-circulates with influenza virus. Laboratory diagnostic methods like DFA and immunocromatography have about $80 \%$ of sensitivity but a significantly lower rate in elderly patients compared to PCR. The clinical impact of this new virus justifies the recommendation to vaccinate traditionally established risk groups and to prescribe antiviral treatment to patients that acquire severe influenza or have risk factors to progress to complications.

Key words: Influenza, H1N1 2009, pandemic, diagnosis, oseltamivir, influenza vaccine.

Palabras clave: Influenza, H1N1 2009, pandemia, diagnóstico, oseltamivir, vacuna antiinfluenza.
\end{abstract}

$\mathrm{D}$ urante el año 2009 en Chile, al igual que en la mayoría de los países en el mundo, la temporada de influenza se caracterizó por la aparición y circulación de un nuevo virus influenza humana, influenza A(H1N1) 2009. En Chile, debido a la escasa disponibilidad de información científica al momento que enfrentamos la epidemia, se tomaron decisiones de diagnóstico y manejo de los casos que en ese momento parecieron las más apropiadas. Fue así como se decidió indicar terapia con oseltamivir a todos los consultantes sobre 5 años de edad con diagnóstico clínico de influenza y apoyados en la confirmación de laboratorio en los niños bajo 5 años de edad, dada la co-circulación con VRS. Este nuevo virus afectó $\sim$ a $2-4 \%$ de la población chilena, estimación basada en los casos registrados que consultaron o en el número de tratamientos con oseltamivir recetados, respectivamente. Si consideramos la estimación de que sólo $1 / 3$ de los casos consultó, podemos decir que la tasa de ataque real fue entre 6 y $12 \%$. El grupo etáreo con mayor incidencia fue el de escolares con una tasa de $4.500 / 100.000$ hab.

De todos los que enfermaron y consultaron a un centro de salud, el $0,56 \%$ requirió de hospitalización por enfermedad grave. En Chile se registraron 1.875 hospitalizaciones por influenza A(H1N1)2009. Si bien los escolares enfermaron con mayor frecuencia que la población general ${ }^{1}$ los con mayor riesgo de presentar una enfermedad grave fueron, en primer lugar los adultos $\geq 60$ años y luego los niños bajo 5 años. El 57\% de los hospitalizados tenía al menos una co-morbilidad.

Durante la primera ola se notificaron 153 muertes a consecuencia de influenza H1N1. La letalidad de la influenza fue de $0,04 \%$ siendo en los $\geq 60$ años 10 veces más alta, $0,44 \%$. De los que fallecieron, $87 \%$ presentaba una enfermedad de base.

La adecuada notificación y el registro centralizado de los casos han permitido con el tiempo evaluar el comportamiento de este nuevo virus de influenza en nuestra población. Actualmente contamos con mayor información en relación a las características clínicas de la enfermedad y grupos de riesgo lo que permite realizar recomendaciones sobre medidas preventivas y terapéuticas como el uso de vacunas de influenza H1N1 y el uso de oseltamivir con una mayor solidez científica.

Con estos antecedentes ¿Qué podemos decir hasta ahora?

\section{¿Qué tan adecuado es el diagnóstico clínico para influenza humana H1N1?}

El diagnóstico clínico de enfermedad tipo influenza (ETI) tiene una sensibilidad para el diagnóstico de influenza, cuando se confirma por reacción de polimerasa en cadena (RPC), de alrededor de $80 \%$. Un estudio realizado en la Clínica Alemana de Santiago mostró una sensibilidad de $84 \%$ comparado con $\mathrm{RPC}^{2}$. La sensibilidad de ETI como forma de diagnóstico varió según los grupos etáreos. 
En el niño bajo 5 años de edad, la sensibilidad disminuyó a $48 \%$ llegando a $25 \%$ bajo 1 año de edad y hasta $59 \%$ entre 1 y 5 años. Sobre los 5 años de edad, la sensibilidad de ETI fue de $62 \%$ alcanzando la mejor correlación en el grupo etáreo entre 15 y 54 años $(80 \%)$ cuando el diagnóstico se realizó con $\mathrm{IFD}^{3}$. Por lo tanto, en los niños pequeños es importante aproximarse al diagnóstico idealmente con confirmación de laboratorio, especialmente si requiere de terapia con antivirales. Hay que considerar que durante el año 2009 hubo co-circulación con VRS, virus predominante en los niños bajo 5 años. En un escenario donde no hay co-circulación de ambos virus la sensibilidad del cuadro clínico podría ser más alta en los pacientes bajo 5 años de edad.

\section{¿Cuál es la sensibilidad y especificidad de los distintos métodos de diagnóstico?}

Los métodos diagnósticos más ampliamente disponibles son la inmunofluorescencia y, en segundo lugar, las pruebas rápidas inmunocromatográficas $\left(\right.$ Test pack $\left.{ }^{\circledR}\right)$. La IFD mostró mejor sensibilidad que las pruebas inmunocromatográficas. En dos estudios realizados en dos centros universitarios, la IFD mostró una sensibilidad de $75 \% 0^{3}$ y de $57,2 \%{ }^{4}$ cuando se comparó con RPC. En estos mismos estudios la prueba inmunocromatográfica mostró una sensibilidad de 59\% y 47,3\% respectivamente 5 .

Estos resultados permiten afirmar, en primer lugar, que las pruebas que utilizan la técnica de inmunofluorescencia tienen mejor sensibilidad que las inmunocromatográficas $\mathrm{y}$, en segundo lugar, que un resultado negativo en pacientes con ETI no permite descartar el diagnóstico. La sensibilidad del diagnóstico clínico, especialmente en el grupo etáreo entre 15 y 54 años, es mejor que las pruebas de diagnóstico de laboratorio.

La especificidad de las técnicas varió entre los distintos estudios entre $87 \%$ y $98 \%$ para la IFD y entre $94 \%$ y $99 \%$ para el test inmunocromatográfico respectivamente.

\section{¿Varía el rendimiento de los distintos métodos de diagnóstico con la edad de los pacientes?}

Los métodos de diagnóstico varían en su sensibilidad y especificidad según los distintos grupos etáreos. Es así como, en los niños el rendimiento de la IFD y de las pruebas rápidas es mucho mejor que en los adultos. La sensibilidad de la IFD fue de $77 \%$ bajo 5 años de edad y de $35 \%$ sobre los 54 años $^{3}$. El grupo de Clínica Alemana mostró una sensibilidad de 58,8\% bajo 3 años de edad y de $37,3 \%$ a partir de los 15 años 5 . La misma situación se repite para las pruebas inmunocromatográficas donde la sensibilidad bajo 5 años de edad fue de $66 \%$ y de $45 \%$ sobre los 54 años ${ }^{2}$. Otro estudio mostró el mismo resultado de $57,1 \%$ bajo los 5 años mientras que sobre dicha edad disminuyó a 45,8\% ${ }^{4}$.

¿Qué podemos aprender de estos estudios? En primer lugar, que para la interpretación adecuada de los resultados de estos métodos de diagnósticos es importante considerar la edad del paciente. Ante la necesidad de confirmación de laboratorio de influenza A (H1N1) 2009 el método de elección en adultos, especialmente sobre 54 años, debería ser la RPC, dada la baja sensibilidad de la IFD y de las pruebas inmunocromatográficas.

\section{¿Cuál es el rol de las vacunas actualmente?}

Chile tiene una larga trayectoria en el uso de vacuna de influenza en los grupos más vulnerables. Es conocido que influenza produce mayor morbilidad y mortalidad en ciertos grupos de personas como los niños pequeños, las mujeres embarazadas, pacientes con algunas enfermedades crónicas y adultos mayores. Esta influenza pandémica no ha sido la excepción. En términos de morbilidad significó un mayor número de hospitalizaciones por influenza que en años anteriores, especialmente en demanda de camas de cuidados críticos. En términos de mortalidad, afectó a grupos etáreos que normalmente no registraban muertes por influenza como es el grupo entre 20 y 64 años y mantuvo el predominio de riesgo de muerte en los adultos sobre 60 años de edad. También se vieron muy afectados las personas con alguna enfermedad crónica de base, siendo la presencia de éstas un factor de riesgo de mortalidad. Por estas razones parece altamente recomendable proteger a los grupos de riesgo, en forma preferencial, si se cuenta con una herramienta como es la vacuna de influenza A (H1N1) 2009.

\section{¿Es segura la vacuna?}

Las vacunas de influenza pandémica son de diversos tipos. La más ampliamente utilizada en Chile para esta temporada 2010 es la fabricada en huevos de gallina embrionados, que contiene $15 \mu \mathrm{g}$ de hemaglutinina, sin adyuvante. Éstas pueden presentarse como producto monovalente A H1N1 o trivalente, es decir asociada a una cepa de influenza B y a una cepa de influenza A H3N2. Los estudios de reactogenicidad y seguridad de estas vacunas muestran efectos secundarios similares, en frecuencia y tipo, a las vacunas de influenza estacional empleadas en años anteriores, siendo los más frecuentes dolor en el sitio de la punción como efecto local y fiebre como efecto sistémico.

Por otro lado, están las vacunas que contienen una sustancia "adyuvante", variable entre las distintas compañías productoras de vacunas, que aumentan la frecuencia e intensidad de la respuesta inmune y, en consecuencia, permiten el uso de una menor cantidad de antígeno para lograr la misma eficacia. Esta tecnología permite producir un mayor número de vacunas y reducir el número de dosis en los niños. De estas vacunas, sólo una de ellas se comercializa en Chile. En relación a estudios previos se mostró una mayor reactogenicidad local y sistémicas en 
las vacunas con adyuvantes comparada con las vacuna sin ellos, sin demostrarse efectos secundarios serios.

En ninguno de los dos tipos de vacunas se ha demostrado una muerte relacionada a ellas habiéndose utilizado muchos millones de dosis durante la temporada de influenza A (H1N1) 2009 en el hemisferio norte. Podemos concluir que son vacunas seguras y eficaces para la prevención de esta enfermedad.

\section{¿Quiénes se deben vacunar?}

Para contestar esta pregunta primero debemos conocer quiénes son las personas que tienen más riesgo de desarrollar una influenza grave al enfermar de influenza. El estudio de los casos chilenos demostró que $0,56 \%$ de los que enfermaron requirieron de hospitalización. Sin embargo, esta tasa fue de $3,47 \%$ en los adultos sobre 60 años y de $1,56 \%$ bajo los 5 años. El cálculo de la edad como factor de riesgo de influenza grave fue estadísticamente significativo en estos dos grupos etáreos y protector en los niños entre 5 y 14 años ${ }^{6}$.

Por otro lado, sabemos que la tasa de letalidad de la influenza pandémica en la población general fue de $0,039 \%$. Sin embargo, esta tasa fue diez veces mayor a partir de los 60 años, alcanzando una tasa de $0,44 \%$. Por lo tanto, la edad sobre 60 años fue un factor de riesgo, estadísticamente significativo, para fallecer a consecuencia de influenza pandémica.

En Chile, otro factor de riesgo para fallecer por influenza fue la presencia de enfermedad crónica. El $87 \%$ de los fallecidos tenía al menos una enfermedad de base comparado con $57 \%$ de los que no fallecieron. La existencia de una co-morbilidad fue significativa como riesgo de fallecer en el grupo etáreo entre 15 y 59 años. Es decir, este grupo tiene riesgo de fallecer por influenza cuando presenta alguna co-morbilidad asociada. Las enfermedades que se asociaron significativamente a riesgo de fallecimiento fueron: consumo de alcohol y drogas, daño hepático crónico, obesidad, genopatías, epilepsia, daño neurológico, EPOC y diabetes mellitus. El embarazo no pudo ser demostrado en Chile como un factor de riesgo por falta de antecedentes; no obstante, por reportes de otros países sabemos que las mujeres embarazadas tienen un riesgo de hospitalización aproximadamente diez veces mayor que la población general y con mayor riesgo de mortalidad. La mayoría de las pacientes cursaban embarazos en su segundo y tercer trimestre.

Ahora entonces estamos en condiciones de responder la pregunta de a quién vacunar.

Basado en los antecedentes que contamos actualmente, parece muy adecuado focalizar la vacunación en los grupos que tienen mayor riesgo de presentar una enfermedad más grave y que requiera hospitalización o en quienes tengan mayor riesgo de fallecer por influenza. Estos grupos son los niños pequeños, mujeres cursando el segundo o tercer trimestre de embarazo, los adultos a partir de los 60 años y los pacientes con algunas de las enfermedades crónicas mencionadas.

\section{¿Cuál es el rol de los antivirales en esta segunda ola?}

Durante la primera ola pandémica en Chile, se adoptó la estrategia de tratar con antivirales, principalmente oseltamivir, a todo paciente sobre 5 años que consultó por ETI, y con influenza confirmada por laboratorio en los niños bajo 5 años. La evaluación de esta estrategia demostró que, comparado con otros países, la tasa de hospitalización por influenza grave fue mucho más baja en Chile, 7,44/100.000 hbtes versus tasas de 69/100.000, 35/100.000 y 23/100.000 en Estados Unidos de América, Argentina, Australia y Nueva Zelandia respectivamente $^{7-10}$. Si fue el uso de oseltamivir a todos los consultantes lo que determinó la baja tasa de hospitalización es difícil de asegurar. Puede haber otros factores involucrados como la consulta precoz de las personas frente a síntomas de influenza y la oportuna evaluación por el personal de salud de los casos de influenza. A pesar del uso generalizado de oseltamivir, la vigilancia de resistencia no detectó en Chile cepas virales con resistencia a este antiviral.

Por otro lado, durante el curso de la epidemia fue evidente que la gran mayoría de las personas cursaron con un cuadro clínico leve, autolimitado y sin complicaciones.

Basado en esto, parece razonable limitar la indicación de terapia con antivirales a las personas que, cursando con un cuadro de influenza, tengan riesgo de evolucionar hacia una enfermedad complicada y a aquellos que estén con una influenza grave, es decir hospitalizados.

\section{¿Es entonces esta influenza pandémica más grave que la influenza estacional?}

La respuesta es sí. Afectó a un mayor de personas, si bien la mayoría de éstas con manifestaciones leves. Produjo un número mayor de hospitalizaciones en grupos etáreos, como los adolescentes y adultos, que normalmente no se hospitalizan por influenza, los pacientes que se hospitalizaron requirieron más frecuentemente uso de camas de cuidado crítico que la influenza estacional y por último, produjo muchas más muertes por infección respiratoria aguda en la población entre 20 y 64 años que en los últimos 5 años anteriores.

Hemos aprendido varias lecciones al mirar hacia atrás y analizar lo ocurrido durante nuestra primera ola pandémica. Con esta evidencia, las estrategias de prevención y manejo deben focalizarse en los grupos de mayor riesgo.

Estas estrategias pueden resumirse en lo siguiente:

- Educar a la población sobre los riesgos reales de la infección por este nuevo virus pandémico. 
- Indicar la vacunación anti-influenza A (H1N1) 2009 para los grupos de riesgo.

- Educar a la población acerca de cuáles son los síntomas y signos de complicación de influenza y recomendar la consulta inmediata frente a la aparición de ellos.

- Indicar terapia antiviral precozmente a los grupos con mayor riesgo de presentar enfermedad grave y de fallecer por influenza aunque no presenten síntomas y signos de complicación.

- Optimizar el uso de camas hospitalarias, especialmente las de cuidados críticos, para enfrentar la mayor demanda que se presentará durante la estación de influenza.

- Iniciar terapia antiviral en todos los pacientes que requieran hospitalización por influenza.

\section{Resumen}

Durante el año 2009 nuestro país vivió la primera ola pandémica causada por el nuevo virus de influenza A
(H1N1) 2009 aparecido en el hemisferio norte a fines de abril del ese año. La tasa de ataque estimada fue entre 6 a $12 \%$ afectando más frecuentemente a los escolares quienes presentaron una enfermedad leve. Los grupos etáreos con mayor riesgo de hospitalización fueron los adultos mayores y los niños bajo 5 años de edad. Tuvieron mayor riesgo de fallecer los adultos mayores y aquellas personas con una co-morbilidad asociada. Aprendimos que el diagnóstico clínico de influenza se confirma por laboratorio en alrededor del $80 \%$ pero tiene una baja correlación en los niños bajo 5 años de edad, especialmente en lactantes bajo 1 año de edad, al circular concomitantemente con VRS. Los métodos de diagnóstico como la IFD y los inmunocromatográficos tienen una sensibilidad que no supera el $80 \%$ y es muy baja en los adultos mayores cuando se compara con PCR. Dado el impacto clínico de este nuevo virus se justifica el uso de vacunación en los grupos de riesgo previamente descritos y el tratamiento con antivirales en los pacientes que cursan con enfermedad grave o con riesgo de evolucionar a una enfermedad más complicada.

\section{Referencias}

1.- Torres J P, O’Ryan M, Herve B, Espinoza R, Acuña $G$, Mañalich J, et al. Impact of the novel influenza A (H1N1) during the 2009 autumnwinter season in a large hospital setting in Santiago, Chile. Clin Infect Dis 2010; 50 (6): 860-8.

2.- Noriega L M, Araos R, Munita J M, Verdugo R, Díaz V, et al. Nuevo virus influenza A (H1N1): características clínicas de 1400 casos en Clínica Alemana de Santiago. Libro de resúmenes XXVI Congreso Chileno de Infectología, Viña del Mar, 2009. Resumen CO 04, pág 16.

3.- Perret C, Vizcaya $C$, Hirsch $T$, Valenzuela $P$, Godoy $\mathrm{P}$, et al. Correlación entre el diagnóstico clínico de síndromes respiratorios y la etiología viral mediante inmunofluorescencia dirécta en el periodo de circulación de influenza A(H1N1) 2009. Libro de resúmenes XXVI Congreso Chileno de Infectología, Viña del Mar 2009. Resumen CO 29, pág 41.

4.- Wilhelm J, Yubero J, Ríos P, Noriega LM,
Figueroa H, González P, et al. Estudio comparativo de dos técnicas para el diagnóstico de nueva cepa de influenza A H1N1: Inmunofluorescencia directa (IFD) versus transcripción reversa y amplificación genética en tiempo real (RT-PCR). Libro de resúmenes XXVI Congreso Chileno de Infectología, Viña del Mar 2009. Resumen CO 32, pág 44.

5.- Wilhelm J, Yubero J, Herrera S, Noriega LM, Figueroa $\mathrm{H}$, et al. Estudio comparativo de dos técnicas para el diagnóstico de influenza A: Examen inmunocromatográfico (test pack) versus amplificación genética en tiempo real (RT Libro de resúmenes -PCR). Libro de resúmenes XXVI Congreso Chileno de Infectología, Viña del Mar 2009. Resumen CO 31, pág 43.

6.- Perret C, Dabanch J, Najera M, González C, Guerrero A, et al. Epidemiología de los casos graves y fatales de influenza pandémica a (H1N1) 2009 en Chile. Libro de resúmenes XXVI Congreso Chileno de Infectología, Viña del Mar 2009. Resumen CO 28, pág 40.
7.- Centers for Diseases control and Prevention. CDC Estimates of 2009 H1N1 influenza sases, hospitalizations and deaths in the United States, April - December 12, 2009. Available on: http:// www.cdc.gov/h1n1flu/estimates_2009_h1n1. $\mathrm{htm}$ (Accedido 31/3/2010)

8.- Ministerio de Salud. Influenza pandémica (H1N1) 2009. República Argentina http:// municipios.msal.gov.ar/h1n1/parte_influenza/ parte-84-30-12-09.pdf (Accedido 31/3/2010)

9.- Australia Government. Department of Health and Ageing. Australian influenza surveillance summary report. No 33,2009 http://www.healthemergency.gov.au/internet/healthemergency/ publishing.nsf/Content/18D06BAC4644C98DC A25763E00823442/\$File/ozflu-no33-2009.pdf Último acceso el 31/3/2010.

10.- Baker M G, Wilson N, Huang Q S, et al. Pandemic influenza $\mathrm{A}(\mathrm{H} 1 \mathrm{~N} 1) \mathrm{v}$ in New Zealand: The experience from April to August 2009. Euro Surveill .2009;14(34):ppi=19319. Available on line:http://www.eurosurveillance. org/ViewArticle. aspx?articleId=19319. 